\title{
Postnatal Prevention of Childhood Obesity in Offspring Prenatally Exposed to Gestational Diabetes mellitus: Where Are We Now?
}

\author{
Camille Dugas $^{a, b, c}$ Julie Perron ${ }^{b} \quad$ Michèle Kearney $^{a, b}$ \\ Roxanne Mercier ${ }^{a} b \quad$ André Tchernof $a, b, c$ Isabelle Marc ${ }^{c}$ \\ S. John Weisnagel ${ }^{c, d}$ Julie Robitaille ${ }^{a, b, c}$ \\ a School of Nutrition, Laval University, Quebec City, QC, Canada; ${ }^{b}$ Institute of Nutrition and \\ Functional Foods (INAF), Laval University, Quebec City, QC, Canada; ${ }^{\mathrm{C}}$ Endocrinology and \\ Nephrology Axis, CHU de Québec Research Center, Quebec City, QC, Canada; dDiabetes \\ Research Unit, Laval University Medical Research Center, Quebec City, QC, Canada
}

\section{Keywords}

Gestational diabetes mellitus · Childhood obesity · Breastfeeding · Nutrition · Physical activity

\begin{abstract}
Children exposed to gestational diabetes mellitus (GDM) in utero are at high risk of developing many health problems such as obesity. There is an urgent need to find new strategies to prevent obesity development among high-risk populations such as those children. Accordingly, the aim of this review was to summarize current knowledge on the postnatal prevention of childhood obesity in offspring born from mothers with GDM. Specifically, this review addresses the impact of breastfeeding, complementary feeding practices as well as dietary intake and physical activity during childhood on obesity risk of children exposed to GDM in utero. Furthermore, breast milk composition of diabetic mothers and its potential impact on growth is discussed. According to the available literature, breastfeeding may reduce obesity risk in children exposed to GDM in utero but a longer duration seems necessary to achieve its protective effect against obesity. Detailed analysis of breast milk composition of mothers with GDM will be necessary to fully understand the relationship between breastfeeding and obesity in this specific population. This review highlights the need for more studies addressing the impact of complementary feeding practices and lifestyle habits during childhood on obesity risk of children exposed to GDM in utero.

(C) 2017 The Author(s)

Published by S. Karger GmbH, Freiburg
\end{abstract}


Dugas et al.: Postnatal Prevention of Childhood Obesity in Offspring Prenatally Exposed to Gestational Diabetes mellitus: Where Are We Now?

\section{Introduction}

Gestational diabetes mellitus (GDM) is defined as hyperglycemia with first onset or recognition during pregnancy [1]. Its prevalence range from 1.2 to $22.3 \%$ depending on population studied or diagnostic criteria used [2]. According to the International Association of the Diabetes and Pregnancy Study Group, almost 18\% of pregnancies are complicated by GDM [3]. This condition leads to an altered fetal environment and children exposed are at high risk of developing many health problems, such as obesity [4]. Childhood obesity is a growing health concern, and there is an urgent need to find new strategies to prevent its development among high-risk populations such as children exposed to GDM in utero. Causes of obesity are multiple, but increasing evidence suggests that infancy could be a critical period during which nutrition would have a programming effect for later health [5]. Furthermore, it is well known that lifestyle habits established during childhood, including physical activity (PA) and nutrition, are also important predictors of childhood obesity risk [6]. This review summarizes the current knowledge regarding the impact of early life nutrition, including breastfeeding and complementary feeding as well as lifestyle habits during childhood on obesity risk of children born from mothers with GDM.

\section{Breastfeeding}

Breast milk (BM) is the ideal food for infants as it contains adequate amounts of energy and nutrients to meet infant's needs [7, 8]. Accordingly, the World Health Organization (WHO) recommends that infants should be exclusively breastfed for the first 6 months of life [9]. Moreover, a recent meta-analysis showed that breastfed infants, when compared to those who have never been breastfed, had a $22 \%$ risk reduction of developing childhood obesity [10]. Results from another meta-analysis suggested that the association between breastfeeding duration and overweight risk was a dose-dependent association where each additional month of breastfeeding was associated with a decrease in the risk of childhood overweight of 4\% [11]. Thereby, while the association between breastfeeding and obesity seems well established among children, impact of breastfeeding on obesity risk among children exposed to GDM in utero is still misunderstood [12]. Indeed, only few studies have been conducted among this population, and the majority of these studies include women with any type of diabetes, not only GDM.

Among these studies, a longitudinal study has been conducted with children exposed to GDM and to type 1 diabetes in utero in order to compare the impact of diabetic BM (DBM) and nondiabetic banked donor BM (BBM) intake during the early postnatal period (1-7 days) on relative body weight at 2 years [13]. All infants in this study received BM from their biological diabetic mother. According to the lactation status of their mother, some of them also received different amounts of BBM. Results showed that infants consuming the highest tertile of DBM had higher relative body weight at 2 years compared to those in the first tertile. On the other hand, consuming the highest amount of BBM was associated with lower body weight at 2 years [13]. However, further investigations within this cohort showed that ingestion of DBM during the 2 nd to 4 th weeks of life was no longer associated with higher body weight at 2 years, when controlling for intake of DBM in the first week of life [14]. These results suggest that the first week of life could be a critical period for nutritional programing of children born from GDM mothers.

On the other hand, results from cohort studies differ depending on the breastfeeding duration and the age at which outcomes were measured. Firstly, in a prospective cohort study conducted among 324 children exposed to GDM in utero, infants breastfed $>3$ months 
Dugas et al.: Postnatal Prevention of Childhood Obesity in Offspring Prenatally Exposed to Gestational Diabetes mellitus: Where Are We Now?

had a $45 \%$ risk reduction of being overweight at 2-8 years, compared to those breastfed $\leq 3$ months [15]. Moreover, Aris et al. [16] demonstrated that in children exposed to GDM in utero those with the greatest DBM intake (during $\geq 4$ months) had accelerated gain in weight and BMI in the first 6 months of life, whereas this was not observed for the next 30 months. Another study including women with pre-existing diabetes, women with GDM, and nondiabetic women evaluated if breastfeeding was protective against childhood obesity and whether it attenuated the impact of in utero exposure to diabetes on adiposity at 6-13 years [17]. Children breastfed $\geq 6$ months had lower BMI, waist circumference, and visceral and subcutaneous abdominal fat than those who were breastfed $<6$ months, irrespective of they were born from mothers with or without diabetes. Furthermore, among children breastfed $>6$ months, there was no difference for all anthropometric measurements between children exposed and unexposed to diabetes in utero [17]. On the other hand, among children breastfed $<6$ months, those exposed to diabetes in utero had higher BMI, waist circumference, visceral and subcutaneous abdominal fat, and subscapular-to-triceps skinfold ratio compared to those unexposed to diabetes [17]. These results suggest that breastfeeding for at least 6 months could attenuate the impact of in utero exposure to diabetes on adiposity in childhood [17]. Furthermore, data from the same cohort were used to evaluate the impact of breastfeeding on BMI growth trajectory from birth to 13 years among children exposed and unexposed to diabetes in utero [18]. Children exposed to diabetes in utero and breastfed $\geq 6$ months tended to have a slower BMI growth velocity from birth to 9 months and from 4 to 13 years compared to those breastfed for a shorter duration [18]. Similar results were seen in children unexposed to diabetes in utero [18]. Moreover, results from the Nurse's Health Study II showed that offspring of mothers with GDM or pre-existing diabetes that were breastfed predominantly, i.e. more BM than formulas, during the first 6 months of life had lower risk of being overweight at 9-14 years when compared to those that had never been breastfed [19]. Any type of breastfeeding for $>9$ months also decreased overweight risk during childhood when compared to children that had never been breastfed [19]. Finally, a study conducted among Hispanic low-income youth exposed to GDM in utero showed that breastfeeding duration of 12 months seemed necessary to reduce obesity prevalence [20]. Indeed, while children breastfed for $\geq 12$ months had a $72 \%$ reduction in obesity prevalence at 2-4 years compared to those who were never breastfed, breastfeeding for a shorter duration ( $<12$ months) was not significantly associated with a decreased prevalence of obesity [20].

Overall, although the majority of studies seems to confer a positive impact of breastfeeding on BMI and adiposity measures (waist circumference, visceral and subcutaneous abdominal fat, and subscapular-to-triceps skinfold ratio) in children exposed to diabetes in utero, the impact of such feeding type on childhood obesity in this population is not known well enough. While any duration of breastfeeding has a positive impact on obesity risk in children born from a nondiabetic mother, longer duration seems necessary to show an effect among children born from diabetic mothers $[14,19,20]$. This difference could possibly be explained by BM composition that is altered by diabetes status but tends to normalize through time among mothers with GDM, as glycemia returns to normal ranges after delivery [21]. Detailed analysis of BM composition will be necessary to fully understand the relationship between breastfeeding and obesity in children exposed to GDM in utero. Furthermore, more studies targeting this specific population, i.e., children exposed to GDM in utero, are needed. Indeed, further studies should include only children exposed to this specific type of diabetes, but not those exposed to type 1 or type 2 diabetes, because effect of diabetes exposure on children's health may be mediated by various mechanisms according to diabetes type [22]. Furthermore, although randomized controlled trials with children receiving either BM or formula is not feasible for ethical reasons, prospective studies should be conducted where BM 
intake is quantitatively measured and data on complementary feeding practices and other lifestyle behaviors of children are collected.

In addition, several meta-analyses demonstrated that obesity risk among children exposed to GDM in utero is attenuated when maternal BMI is taken into account in analyses $[23,24]$. Thus, it has been demonstrated that being born from a mother with both GDM and overweight had the strongest effect on childhood obesity risk, when compared to mothers with only GDM or overweight [25]. The majority of studies in this section adjusted their results for maternal BMI, but some have not, which could lead to divergent conclusions [17, $18,20]$. Finally, birth weight is also considered as a significant predictor of childhood obesity risk [26]. In GDM pregnancy, maternal hyperglycemia leads to fetal hyperinsulinemia, which increases fetal growth and then the risk of being born with a high birth weight [27]. Some authors suggested that the association between exposure to GDM and obesity risk in childhood would be partially explained by elevated birth weight, highlighting the importance to consider this cofactor in analyses [28]. The majority of studies presented in this section adjusted their results for birth weight $[13-15,19,20]$.

\section{Gestational Diabetes mellitus and Breast Milk Composition}

Benefits of breastfeeding on children's health are likely due to the unique composition of BM, a particular food that cannot be entirely replicated in formulas. As mentioned above, breastfed infants present a lower risk of developing obesity when compared to formula-fed infants, and this could be explained in part by protein and energy content that is lower in BM than in formulas $[8,29]$. Furthermore, BM contains growth factors and hormones involved in appetite regulation [30]. However, DBM composition differs from BM of healthy mothers, suggesting that this altered BM composition could possibly affect children's growth and health.

Some studies showed that DBM contains higher glucose and lower lipid levels than BM of nondiabetic women, although protein and calorie content does not seem to be altered by maternal diabetes status [31-33]. Women with a pregnancy complicated by type 1 diabetes but with a good glycemic control during lactation would have similar concentrations of cholesterol, triglycerides, lactose, protein, and glucose as well as a similar fatty acid profile in their BM than women without diabetes [34]. We can speculate that composition of BM of women with GDM (GDMBM) would also depend on glycemic control, much like that in type 1 diabetic mothers. Moreover, considering that glycemia of women with GDM generally returns to normal ranges progressively after delivery [35], the timing of GDMBM collection is likely to influence its composition.

Among the few studies that have been conducted among women with GDM, one of them showed that colostrum of GDM mothers presented an altered whey proteome [36]. Another study showed no major difference regarding amino acid content of GDMBM when compared to BM of nondiabetic women [37]. Further studies are needed to understand the impact of these findings on children's health.

Some studies also evaluated hormone content of GDMBM in the past few years. Firstly, Ley et al. [38] showed that metabolic abnormalities during pregnancy, including insulin resistance, lower insulin sensitivity or glucose intolerance, but not GDM diagnosis, was associated with high insulin content in BM collected at 3 months postpartum. Furthermore, Aydin et al. [21] studied ghrelin levels in GDMBM, a peptide hormone involved in energy balance and known for increasing appetite [39]. Aydin et al. found that colostrum of mothers with GDM had lower levels of ghrelin than did mothers without GDM $[21,40]$. However, in mature milk (15 days postpartum), ghrelin levels were similar in both GDMBM and BM of nondiabetic 
mothers, but remained lower in women with pre-existing diabetes included in that study [21]. Considering that GDM mothers were normoglycemic at day 15 and that participants with pre-existing diabetes had high glycemic values at day 15 , this suggests that ghrelin levels in BM may depend on the glycemic control of these mothers. Besides being involved in energy homeostasis, ghrelin level has been negatively associated with weight gain in infancy, suggesting that children exposed to lower levels of ghrelin from colostrum of mothers with GDM could possibly have a lower weight gain in early life [41].

Aydin et al. [40] also evaluated nesfatin-1 concentration in GDMBM, a peptide derived from the precursor peptide nucleobindin 2 which has anorexigenic effects and reduced weight gain in rats [42]. The authors found that colostrum of GDM mothers contains significantly less nesfatin- 1 than did colostrum of non-GDM mothers and that nesfatin- 1 concentration in mature BM was lower in GDM mothers, but the difference did not reach statistical significance, possibly due to a normalization of their glycemia through time [40]. Thus, infants exposed to BM containing a lower nesfatin-1 concentration in the first week of life could be hungrier and therefore drink more BM than infants fed with normoglycemic BM. In fact, it has been demonstrated that plasma nesfatin-1 concentration was negatively correlated to caloric intake in newborns and that caloric and carbohydrate intakes tend to be higher in obese patients with lower circulating nesfatin-1 levels $[43,44]$.

The same group of investigators evaluated adropin and irisin concentrations in GDMBM. Adropin is a peptide hormone, encoded by the energy homeostasis-associated gene (Enho) that is involved in the regulation of metabolic homeostasis in mice [45, 46]. Aydin et al. [47] found that women with GDM had lower adropin concentrations in their colostrum than women without GDM, but that adropin levels were not different in transitional (7 days postpartum) and mature milk between groups. It has been demonstrated that adropin deficiency is associated with higher body fat mass in mice, suggesting that being exposed to lower levels of adropin from GDMBM may also lead to an increased body fat mass in children, as in mice [46]. Furthermore, irisin is a myokine involved in thermogenesis by inducing conversion of white adipose tissue into brown adipose tissue [48]. Aydin et al. [47] found that colostrum and transitional milk of GDM mothers had a lower irisin concentration than those of control mothers, but irisin levels were similar between groups in mature milk. Exposing infants to lower irisin levels at the very beginning of life could result in less thermogenesis and therefore in a higher body fat mass. Finally, microRNAs are posttranscriptional regulators of gene expression that are involved in many biological phenomena, e.g. insulin secretion $[49,50]$. Altered microRNA expression has been detected in some pathologies, including GDM in which the altered microRNA signature may contribute to macrosomia in the offspring [51]. Given that $\mathrm{BM}$ is rich in microRNAs and that those components are transmitted to the breastfed infant via the digestive tract $[52,53]$, it would be interesting to characterize microRNA content of GDMBM in order to better understand the effect of breastfeeding on growth of children born from mothers with GDM.

In conclusion, GDMBM presents several alterations that could possibly affect offspring growth but seems to be normalized after only a few weeks, probably, at least in part, due to normalization of glycemia. These findings point to potential mechanisms involved in the beneficial effect of longer duration of breastfeeding for children exposed to GDM on obesity risk. Nevertheless, these suggested mechanisms still need to be investigated, and more studies are needed to fully understand their impact on children's health. 
Dugas et al.: Postnatal Prevention of Childhood Obesity in Offspring Prenatally Exposed to Gestational Diabetes mellitus: Where Are We Now?

\section{Complementary Feeding}

As mentioned earlier, the WHO recommends that infants should be exclusively breastfed for the first 6 months of life [9]. After this period, infants are physically ready to receive complementary foods, i.e. solid foods and liquids other than BM and formulas [54]. Despite this recommendation, a recent study conducted in Canada showed that only $19 \%$ of mothers waited until 6 months to introduce complementary foods [55]. The complementary feeding period is characterized by an increase in protein intakes, especially in breastfed infants [56]. Indeed, $5 \%$ of BM energy content is provided by proteins, while protein content of family foods is generally 3-4 times higher [56]. Given that high protein intake in early life is associated with higher BMI at 2 years, introducing complementary foods rich in protein at young ages could possibly affect the growth trajectory of children [57]. On the other hand, less is known about the impact of early introduction of sugar on obesity risk [58]. However, it has been suggested that added sugar intake during infancy enhances taste preference for sweet foods and may therefore affect diet quality later in life [59], an important determinant of obesity development. Finally, it has been suggested that introducing solid foods in the infant's diet increases caloric intake, especially in formula-fed infants [60]. Indeed, breastfed infants self-regulate their intakes when solid foods are introduced, a notion that was not observed among formula-fed infants who were consuming significantly more calories per day in the first 8 months of life when solid foods were introduced before 13 weeks, compared to those introduced to solids after 22 weeks $[60,61]$. Thus, the complementary feeding period is a time of transition and could have a significant impact on children's later health.

Whether the timing of complementary food introduction influences obesity risk is still a matter of debate, and, to our knowledge, no study has been conducted specifically among children exposed to GDM in utero, neither among children exposed to diabetes in utero. Two recent systematic reviews $[62,63]$ showed no evidence that timing of introduction of solid foods influences growth in children. On the other hand, another literature review [64] showed that introducing solid food before 4 months was associated with higher risk of developing childhood obesity, although introducing solids between 4 and 6 months instead of waiting until 6 months does not seem to be associated with obesity development. Conflicting results can possibly be explained by many factors such as heterogeneity in the definition of early food introduction, the fact that outcomes are observed at different stages of childhood, and lack of consideration of important confounding factors such as breastfeeding, maternal BMI and birth weight. Further studies should be conducted, especially among children exposed to GDM in utero who are at high risk of developing obesity later in life [4]. Studies should take into account quantity and quality of foods introduced to children as different food components may have different effects on obesity development $[57,59,65]$.

\section{Dietary Intake and Physical Activity during Childhood}

After infancy, childhood is an important period during which lifestyle shaping can track into adulthood [66]. Among lifestyle behaviors, it is well established that both healthy diet and PA have a strong impact on obesity prevention in children [6], but little is known on the impact of those behaviors on the health of children born from mothers with GDM.

We know that food intake, energy expenditure, and resting metabolic rate are similar among children exposed and those unexposed to GDM or diabetes in utero [67-70]. Indeed, in a study conducted among Pima Indian children, those born from diabetic mothers consumed the same amount of calories per day than those born from mothers who developed diabetes after pregnancy [70]. Furthermore, according to results from the CHASE study, children born 
Dugas et al.: Postnatal Prevention of Childhood Obesity in Offspring Prenatally Exposed to Gestational Diabetes mellitus: Where Are We Now?

from women with GDM or type 1 diabetes had the same dietary pattern than children unexposed to diabetes in utero, except for orange juice consumption which was slightly lower in children born from diabetic mothers [69]. To our knowledge, only one study has specifically measured the impact of lifestyle behaviors on obesity risk in children exposed to GDM in utero. In that study, Zhang and collaborators [71] showed that TV watching time $>1 \mathrm{~h} /$ day was associated with increased risk of obesity and central obesity in a population of children aged 1-5 years born from mothers with GDM in China. However, they found no association of indoor activity, outdoor activity, and sleeping time with the risk of obesity or central obesity [71].

Furthermore, few studies conducted secondary analyses on this topic and showed conflicting results. First, Crume et al. [72] showed that BMI and waist circumference were higher in children exposed to GDM in utero compared to children unexposed even when adjusting for current behavioral confounders such as daily energy intake or PA level. Another study also demonstrated that exposure to high maternal glucose levels during pregnancy was correlated to current adiposity of children aged 5-10 years independently of current energy intake and PA level of children [73]. Gillman et al. [28] found that the relative risk for overweight in adolescence remained unchanged when adjusting for PA, energy intake, and television watching in children exposed to GDM. Finally, Zhao et al. [74] showed that BMI z score, waist circumference $\mathrm{z}$ score, and body fat $\mathrm{z}$ score were higher in children born from mothers with GDM than in those unexposed to GDM in utero, even after adjusting for lifestyle habits such as unhealthy diet pattern scores, PA level, sleeping time, and sedentary time. However, associations were no longer significant after adjusting for current maternal BMI [74]. On the other hand, a sibling study where exposure to the environment - such as lifestyle - was similar showed that there was no difference in BMI between siblings exposed versus those unexposed to GDM in utero [75]. These results suggest that the environmental influence of lifestyle habits has a stronger influence than intrauterine exposure to GDM in the development of obesity in children, because siblings generally have similar lifestyle habits [75-77].

Overall, results suggest that food intake and PA levels are similar among children exposed versus those unexposed to GDM, but the impact of such behaviors on obesity risk among these high risk children is still unknown. Further research addressing directly the question is needed.

\section{Conclusion}

Considering that children exposed to GDM in utero represent a subgroup at high risk of developing obesity, prevention strategies targeting modifiable factors among this specific population are needed. This review highlights the lack of studies conducted among children exposed to GDM in utero as the majority of the studies presented include children born from mothers with any type of diabetes. As different types of diabetes can have different impacts on children's health [22], more studies targeting this specific population are needed.

Overall, this review showed that breastfeeding may reduce childhood obesity risk in children exposed to diabetes in utero, but longer duration is needed to achieve the protective effects of BM against obesity. More studies are required to examine GDMBM composition and its effects on obesity risk in their offspring. In addition, more studies are needed on the association between timing of solid food introduction and obesity risk as well as on the effect of childhood lifestyle habits on obesity risk among children exposed to GDM in utero. Studies should also take into account maternal and paternal BMI in addition to birth weight when assessing the association between early nutrition or lifestyle habits and obesity risk in childhood due to their impact on this outcome. 


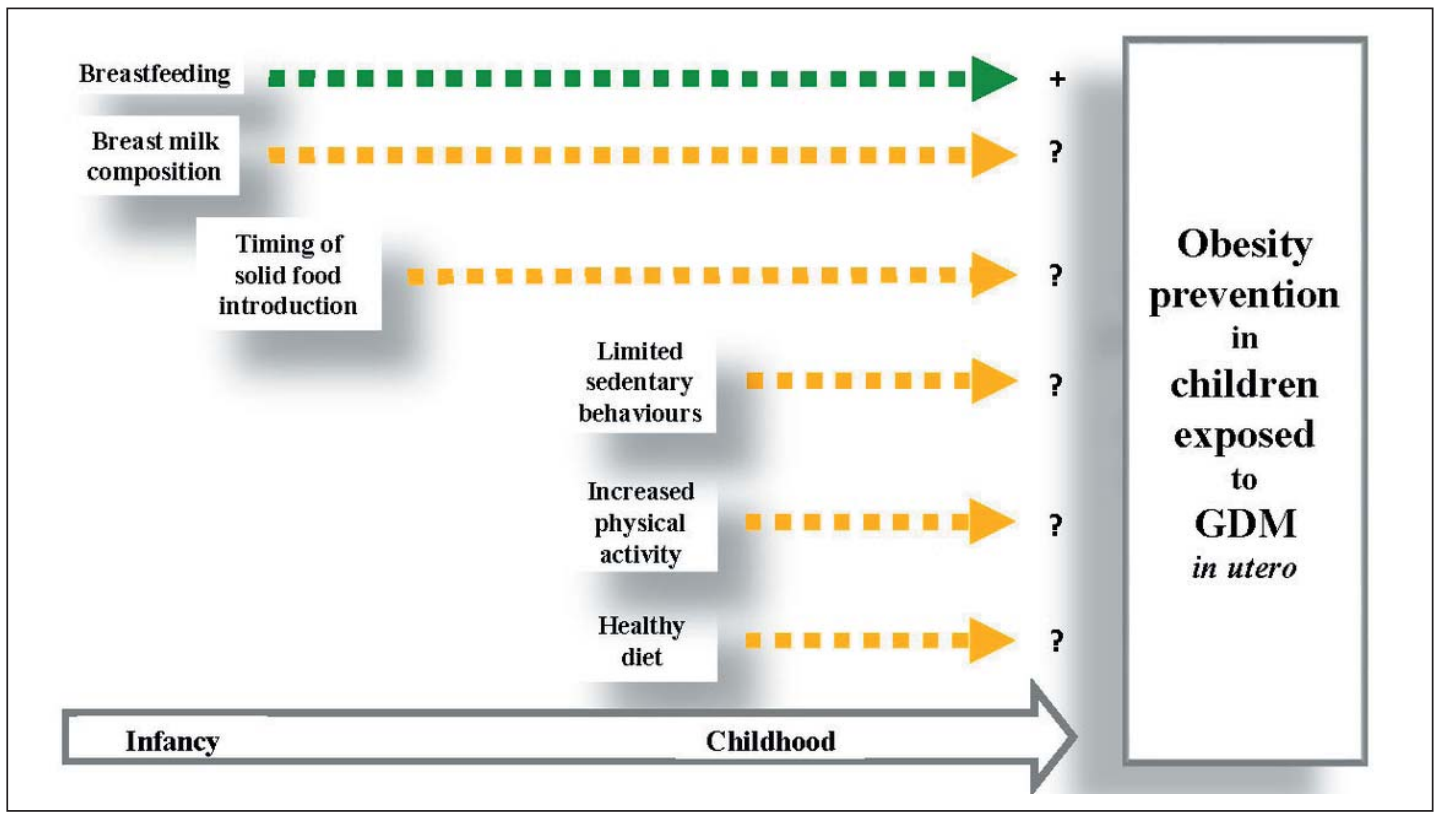

Fig. 1. Impact of early nutrition and PA during infancy and childhood on obesity prevention in children exposed to GDM in utero. Postnatal factors taking place in infancy and childhood that could play a role in obesity prevention and discussed in this review are represented in small boxes. Yellow arrows indicate a lack of scientific evidence regarding the impact of those factors on obesity prevention in children exposed to GDM in utero. The green arrow indicates a potential beneficial association between breastfeeding and obesity prevention in children exposed to GDM in utero.

As shown in figure 1, this review highlighted the gap in the current literature regarding the effectiveness of postnatal prevention strategies for childhood obesity in offspring prenatally exposed to GDM. Although evidence suggests that the prenatal period is a critical phase in child development and later health, mounting evidence point toward early postnatal life in the plastic phase of development [78]. Further studies targeting this specific period are needed to enhance childhood obesity prevention programs in high-risk children such as those exposed to GDM in utero.

\section{Acknowledgments}

This work was supported by the Canadian Diabetes Association (Grand number: OG-3-14-4543-JR, 2014-2017). Camille Dugas is recipient of a master research award from the Canadian Institutes of Health Research. All co-authors revised the final version of the paper.

\section{Disclosure Statement}

Authors reported no potential conflict of interest relevant to this article. 


\section{References}

1 Coustan DR: Gestational diabetes mellitus. Clin Chem 2013;59:1310-1321.

2 Chen L, Mayo R, Chatry A, Hu G: Gestational diabetes mellitus: its epidemiology and implication beyond pregnancy. Curr Epidemiol Rep 2016;3:1-11.

3 Metzger B, Gabbe SG, Persson B, Buchanan TA, Catalano P, Damm P, Dyer A, de Leiva A, Hod M, Kitzmiller J, Lowe L, McIntyre HD, Oats J, Omori Y, Schmidt M, Balaji V, Callaghan W, Chen R, Conway D, Corcoy R, Coustan D, Dabelea D, Fagen C, Feig D, Ferrara A, Geil P, Hadden D, Hillier TA, Hiramatsu Y, Houde G, Inturissi M, Jang HC, Jovanovic L, Kautsky-Willer A, Kirkman MS, Kjos S, Landon MB, Lapolla A, Lowe J, Mathiesen H, Mello G, Meltzer SJ, Moore T, Nolan CJ, Ovesen P, Pettitt P, Reader DM, Rowan J, Sacks D, Schaefer-Graf U, Seshiah V, Simmons D, Sugiyama T, Trimble E, Varma S, Yang H, Yasuhi I: International Association of Diabetes and Pregnancy Study Groups recommendations on the diagnosis and classification of hyperglycemia in pregnancy. Diabetes Care 2010;33:676-682.

4 Chandler-Laney PC, Bush NC, Granger WM, Rouse DJ, Mancuso MS, Gower BA: Overweight status and intrauterine exposure to gestational diabetes are associated with children's metabolic health. Pediatr Obes 2012; $7: 44-52$

5 Hanson MA, Gluckman PD: Early developmental conditioning of later health and disease: physiology or pathophysiology? Physiol Rev 2014;94:1027-1076.

6 World Health Organization: Childhood Obesity Prevention. Geneva, WHO, 2012.

7 Lonnerdal B: Nutritional and physiologic significance of human milk proteins. Am J Clin Nutr 2003;77:1537S$1543 \mathrm{~S}$.

8 Hester SN, Hustead DS, Mackey AD, Singhal A, Marriage BJ: Is the macronutrient intake of formula-fed infants greater than breast-fed infants in early infancy? J Nutr Metab 2012;2012:891201.

9 World Health Organization: Report of the Expert Consultation on the Optimal Duration of Exclusive Breastfeeding. Geneva, WHO, 2001.

10 Yan J, Liu L, Zhu Y, Huang G, Wang PP: The association between breastfeeding and childhood obesity: a metaanalysis. BMC Public Health 2014;14:1267.

11 Harder T, Bergmann R, Kallischnigg G, Plagemann A: Duration of breastfeeding and risk of overweight: a metaanalysis. Am J Epidemiol 2005;162:397-403.

12 Gunderson EP: Breastfeeding after gestational diabetes pregnancy: subsequent obesity and type 2 diabetes in women and their offspring. Diabetes Care 2007;30(suppl 2):S161-168.

13 Plagemann A, Harder T, Franke K, Kohlhoff R: Long-term impact of neonatal breast-feeding on body weight and glucose tolerance in children of diabetic mothers. Diabetes Care 2002;25:16-22.

14 Rodekamp E, Harder T, Kohlhoff R, Franke K, Dudenhausen JW, Plagemann A: Long-term impact of breastfeeding on body weight and glucose tolerance in children of diabetic mothers: role of the late neonatal period and early infancy. Diabetes Care 2005;28:1457-1462.

15 Schaefer-Graf UM, Hartmann R, Pawliczak J, Passow D, Abou-Dakn M, Vetter K, Kordonouri O: Association of breast-feeding and early childhood overweight in children from mothers with gestational diabetes mellitus. Diabetes Care 2006;29:1105-1107.

16 Aris IM, Soh SE, Tint MT, Saw SM, Rajadurai VS, Godfrey KM, Gluckman PD, Yap F, Chong YS, Lee YS: Associations of infant milk feed type on early postnatal growth of offspring exposed and unexposed to gestational diabetes in utero. Eur J Nutr 2017;56:55-64.

17 Crume TL, Ogden L, Maligie M, Sheffield S, Bischoff KJ, McDuffie R, Daniels S, Hamman RF, Norris JM, Dabelea D: Long-term impact of neonatal breastfeeding on childhood adiposity and fat distribution among children exposed to diabetes in utero. Diabetes Care 2011;34:641-645.

18 Crume TL, Ogden LG, Mayer-Davis EJ, Hamman RF, Norris JM, Bischoff KJ, McDuffie R, Dabelea D: The impact of neonatal breast-feeding on growth trajectories of youth exposed and unexposed to diabetes in utero: the EPOCH Study. Int J Obes 2012;36:529-534.

19 Mayer-Davis EJ, Rifas-Shiman SL, Zhou L, Hu FB, Colditz GA, Gillman MW: Breast-feeding and risk for childhood obesity: does maternal diabetes or obesity status matter? Diabetes Care 2006;29:2231-2237.

20 Shearrer GE, Whaley SE, Miller SJ, House BT, Held T, Davis JN: Association of gestational diabetes and breastfeeding on obesity prevalence in predominately Hispanic low-income youth. Pediatr Obes 2015;10:165-171.

21 Aydin S, Geckil H, Karatas F, Donder E, Kumru S, Kavak EC, Colak R, Ozkan Y, Sahin I: Milk and blood ghrelin level in diabetics. Nutrition 2007;23:807-811.

22 Boerschmann H, Pflüger M, Henneberger L, Ziegler A-G, Hummel S: Prevalence and predictors of overweight and insulin resistance in offspring of mothers with gestational diabetes mellitus. Diabetes Care 2010;33:1845.

23 Kim SY, Sharma AJ, Callaghan WM: Gestational diabetes and childhood obesity: what is the link? Curr Opin Obstet Gynecol 2012;24:376-381.

24 Philipps LH, Santhakumaran S, Gale C, Prior E, Logan KM, Hyde MJ, Modi N: The diabetic pregnancy and offspring BMI in childhood: a systematic review and meta-analysis. Diabetologia 2011;54:1957-1966.

25 Pirkola J, Pouta A, Bloigu A, Hartikainen AL, Laitinen J, Jarvelin MR, Vaarasmaki M: Risks of overweight and abdominal obesity at age 16 years associated with prenatal exposures to maternal prepregnancy overweight and gestational diabetes mellitus. Diabetes Care 2010;33:1115-1121.

26 Yu ZB, Han SP, Zhu GZ, Zhu C, Wang XJ, Cao XG, Guo XR: Birth weight and subsequent risk of obesity: a systematic review and meta-analysis. Obes Rev 2011;12:525-542. 
27 Kc K, Shakya S, Zhang H: Gestational diabetes mellitus and macrosomia: a literature review. Ann Nutr Metab 2015;66(suppl 2):14-20.

28 Gillman MW, Rifas-Shiman S, Berkey CS, Field AE, Colditz GA: Maternal gestational diabetes, birth weight, and adolescent obesity. Pediatrics 2003;111:e221-226.

29 Owen CG, Martin RM, Whincup PH, Smith GD, Cook DG: Effect of infant feeding on the risk of obesity across the life course: a quantitative review of published evidence. Pediatrics 2005;115:1367-1377.

30 Savino F, Benetti S, Liguori SA, Sorrenti M, Cordero Di Montezemolo L: Advances on human milk hormones and protection against obesity. Cell Mol Biol (Noisy-le-Grand) 2013;59:89-98.

31 Whitmore TJ, Trengove NJ, Graham DF, Hartmann PE: Analysis of insulin in human breast milk in mothers with type 1 and type 2 diabetes mellitus. Int J Endocrinol 2012;2012:296368.

32 Butte NF, Garza C, Burr R, Goldman AS, Kennedy K, Kitzmiller JL: Milk composition of insulin-dependent diabetic women. J Pediatr Gastroenterol Nutr 1987;6:936-941.

33 Morceli G, Franca EL, Magalhaes VB, Damasceno DC, Calderon IM, Honorio-Franca AC: Diabetes induced immunological and biochemical changes in human colostrum. Acta Paediatr 2011;100:550-556.

34 van Beusekom CM, Zeegers TA, Martini IA, Velvis HJ, Visser GH, van Doormaal JJ, Muskiet FA: Milk of patients with tightly controlled insulin-dependent diabetes mellitus has normal macronutrient and fatty acid composition. Am J Clin Nutr 1993;57:938-943.

35 Buchanan TA, Xiang AH, Page KA: Gestational diabetes mellitus: risks and management during and after pregnancy. Nat Rev Endocrinol 2012;8:639-649.

36 Grapov D, Lemay DG, Weber D, Phinney BS, Azulay Chertok IR, Gho DS, German JB, Smilowitz JT: The human colostrum whey proteome is altered in gestational diabetes mellitus. J Proteome Res 2015;14:512-520.

37 Klein K, Bancher-Todesca D, Graf T, Garo F, Roth E, Kautzky-Willer A, Worda C: Concentration of free amino acids in human milk of women with gestational diabetes mellitus and healthy women. Breastfeed Med 2013; 8:111-115.

38 Ley SH, Hanley AJ, Sermer M, Zinman B, O'Connor DL: Associations of prenatal metabolic abnormalities with insulin and adiponectin concentrations in human milk. Am J Clin Nutr 2012;95:867-874.

39 Kojima M, Kangawa K: Ghrelin: structure and function. Physiol Rev 2005;85:495-522.

40 Aydin S: The presence of the peptides apelin, ghrelin and nesfatin-1 in the human breast milk, and the lowering of their levels in patients with gestational diabetes mellitus. Peptides 2010;31:2236-2240.

41 Savino F, Liguori SA, Fissore MF, Oggero R, Silvestro L, Miniero R: Serum ghrelin concentration and weight gain in healthy term infants in the first year of life. J Pediatr Gastroenterol Nutr 2005;41:653-659.

42 Stengel A, Goebel M, Tache Y: Nesfatin-1:a novel inhibitory regulator of food intake and body weight. Obesity Rev 2011;12:261-271.

43 Cheng YY, Zhao XM, Cai BP, Ma LN, Yin JY, Song GY: Nesfatin-1 in newborns: relationship with endocrine and metabolic and anthropometric measures. J Peditr Endocrinol Metab 2012;25:727-732.

44 Mirzaei K, Hossein-Nezhad A, Keshavarz SA, Koohdani F, Eshraghian MR, Saboor-Yaraghi AA, Hosseini S, Chamari M, Zareei M, Djalali M: Association of nesfatin-1 level with body composition, dietary intake and resting metabolic rate in obese and morbid obese subjects. Diabetes Metab Syndr 2015;9:292-298.

45 Kumar KG, Trevaskis JL, Lam DD, Sutton GM, Koza RA, Chouljenko VN, Kousoulas KG, Rogers PM, Kesterson RA, Thearle M, Ferrante AW, Jr., Mynatt RL, Burris TP, Dong JZ, Halem HA, Culler MD, Heisler LK, Stephens JM, Butler AA: Identification of adropin as a secreted factor linking dietary macronutrient intake with energy homeostasis and lipid metabolism. Cell metabolism 2008;8:468-481.

46 Ganesh Kumar K, Zhang J, Gao S, Rossi J, McGuinness OP, Halem HH, Culler MD, Mynatt RL, Butler AA: Adropin deficiency is associated with increased adiposity and insulin resistance. Obesity (Silver Spring) 2012;20: 1394-1402.

47 Aydin S, Kuloglu T, Aydin S: Copeptin, adropin and irisin concentrations in breast milk and plasma of healthy women and those with gestational diabetes mellitus. Peptides 2013;47:66-70.

48 Bostrom P, Wu J, Jedrychowski MP, Korde A, Ye L, Lo JC, Rasbach KA, Bostrom EA, Choi JH, Long JZ, Kajimura S, Zingaretti MC, Vind BF, Tu H, Cinti S, Hojlund K, Gygi SP, Spiegelman BM: A PGC1-alpha-dependent myokine that drives brown-fat-like development of white fat and thermogenesis. Nature 2012;481:463-468.

49 Bartel DP: MicroRNAs: genomics, biogenesis, mechanism, and function. Cell 2004;116:281-297.

50 Melnik BC, John SM, Schmitz G: Milk is not just food but most likely a genetic transfection system activating mTORC1 signaling for postnatal growth. Nutr J 2013;12:103.

51 Li J, Song L, Zhou L, Wu J, Sheng C, Chen H, Liu Y, Gao S, Huang W: A MicroRNA signature in gestational diabetes mellitus associated with risk of macrosomia. Cell Physiol Biochem 2015;37:243-252.

52 Kosaka N, Izumi H, Sekine K, Ochiya T: microRNA as a new immune-regulatory agent in breast milk. Silence 2010;1:7.

53 Zhou Q, Li M, Wang X, Li Q, Wang T, Zhu Q, Zhou X, Wang X, Gao X, Li X: Immune-related microRNAs are abundant in breast milk exosomes. Int J Biol Sci 2012;8:118-123.

54 Public Health Agency of Canada: Breastfeeding \& Infant Nutrition. 2014. www.phac-aspc.gc.ca/hp-ps/dca-dea/ stages-etapes/childhood-enfance_0-2/nutrition/index-eng.php (last accessed July 27, 2017).

55 Fegan S, Bassett E, Peng Y, Steel O'Connor K: Adherence to complementary feeding recommendations for infants and implications for public health. Public Health Nutr 2015:1-12.

56 Michaelsen KF, Greer FR: Protein needs early in life and long-term health. Am J Clin Nutr 2014;99:718S-722S. 
Dugas et al.: Postnatal Prevention of Childhood Obesity in Offspring Prenatally

Exposed to Gestational Diabetes mellitus: Where Are We Now?

57 Putet G, Labaune JM, Mace K, Steenhout P, Grathwohl D, Raverot V, Morel Y, Picaud JC: Effect of dietary protein on plasma insulin-like growth factor-1, growth, and body composition in healthy term infants: a randomised, double-blind, controlled trial (Early Protein and Obesity in Childhood (EPOCH) study). Br J Nutr 2016;115: 271-284.

58 Poskitt EM, Breda J: Complementary feeding and non communicable diseases: current knowledge and future research needs. Nutr Metab Cardiovasc Dis 2012;22:819-822.

59 Foterek K, Buyken AE, Bolzenius K, Hilbig A, Nothlings U, Alexy U: Commercial complementary food consumption is prospectively associated with added sugar intake in childhood. Br J Nutr 2016;115:20672074.

60 Grote V, Schiess SA, Closa-Monasterolo R, Escribano J, Giovannini M, Scaglioni S, Stolarczyk A, Gruszfeld D, Hoyos J, Poncelet P, Xhonneux A, Langhendries JP, Koletzko B: The introduction of solid food and growth in the first $2 \mathrm{y}$ of life in formula-fed children: analysis of data from a European cohort study. Am J Clin Nutr 2011; 94:1785S-1793S.

61 Heinig MJ, Nommsen LA, Peerson JM, Lonnerdal B, Dewey KG: Intake and growth of breast-fed and formulafed infants in relation to the timing of introduction of complementary foods: the DARLING study. Davis Area Research on Lactation, Infant Nutrition and Growth. Acta Paediatr 1993;82:999-1006.

62 Vail B, Prentice P, Dunger DB, Hughes IA, Acerini CL, Ong KK: Age at weaning and infant growth: primary analysis and systematic review. J Pediatr 2015;167:317-324, e311.

63 Moorcroft KE, Marshall JL, McCormick FM: Association between timing of introducing solid foods and obesity in infancy and childhood: a systematic review. Matern Child Nutr 2011;7:3-26.

64 Daniels L, Mallan KM, Fildes A, Wilson J: The timing of solid introduction in an 'obesogenic' environment: a narrative review of the evidence and methodological issues. Aust N Z J Public Health 2015;39:366-373.

65 Agostoni C, Baselli L, Mazzoni MB: Early nutrition patterns and diseases of adulthood: a plausible link? Eur J Intern Med 2013;24:5-10.

66 Telama R: Tracking of physical activity from childhood to adulthood: a review. Obesity Facts 2009;2:187-195.

67 Egeland GM, Meltzer SJ: Following in mother's footsteps? Mother-daughter risks for insulin resistance and cardiovascular disease 15 years after gestational diabetes. Diabet Med 2010;27:257-265.

68 Salbe AD, Fontvieille AM, Pettitt DJ, Ravussin E: Maternal diabetes status does not influence energy expenditure or physical activity in 5-year-old Pima Indian children. Diabetologia 1998;41:1157-1162.

69 Kvehaugen AS, Andersen LF, Staff AC: Dietary intake and physical activity in women and offspring after pregnancies complicated by preeclampsia or diabetes mellitus. Acta Obstet Gynecola Scand 2010;89:1486-1490.

70 Gluck ME, Venti CA, Lindsay RS, Knowler WC, Salbe AD, Krakoff J: Maternal influence, not diabetic intrauterine environment, predicts children's energy intake. Obesity (Silver Spring) 2009;17:772-777.

71 Zhang T, Wang P, Liu H, Wang L, Li W, Leng J, Li N, Zhang S, Qi L, Tuomilehto J, Yu Z, Yang X, Hu G: Physical activity, TV watching time, sleeping, and risk of obesity and hyperglycemia in the offspring of mothers with gestational diabetes mellitus. Sci Rep 2017;7:41115.

72 Crume TL, Ogden L, West NA, Vehik KS, Scherzinger A, Daniels S, McDuffie R, Bischoff K, Hamman RF, Norris JM, Dabelea D: Association of exposure to diabetes in utero with adiposity and fat distribution in a multiethnic population of youth: the Exploring Perinatal Outcomes among Children (EPOCH) Study. Diabetologia 2011; 54:87-92.

73 Chandler-Laney PC, Bush NC, Rouse DJ, Mancuso MS, Gower BA: Maternal glucose concentration during pregnancy predicts fat and lean mass of prepubertal offspring. Diabetes Care 2011;34:741-745.

74 Zhao P, Liu E, Qiao Y, Katzmarzyk PT, Chaput JP, Fogelholm M, Johnson WD, Kuriyan R, Kurpad A, Lambert EV, Maher C, Maia JA, Matsudo V, Olds T, Onywera V, Sarmiento OL, Standage M, Tremblay MS, Tudor-Locke C, Hu G: Maternal gestational diabetes and childhood obesity at age 9-11:results of a multinational study. Diabetologia 2016;59:2339-2348.

75 Nilsson C, Carlsson A, Landin-Olsson M: Increased risk for overweight among Swedish children born to mothers with gestational diabetes mellitus. Pediatr Diabetes 2014;15:57-66.

76 Simonen RL, Perusse L, Rankinen T, Rice T, Rao DC, Bouchard C: Familial aggregation of physical activity levels in the Quebec Family Study. Med Sci Sports Exerc 2002;34:1137-1142.

77 Wolnicka K, Taraszewska AM, Jaczewska-Schuetz J, Jarosz M: Factors within the family environment such as parents' dietary habits and fruit and vegetable availability have the greatest influence on fruit and vegetable consumption by Polish children. Public Health Nutr 2015;18:2705-2711.

78 Gillman MW, Ludwig DS: How early should obesity prevention start? N Engl J Med 2013;369:2173-2175. 